(c) American Dairy Science Association, 2004.

\title{
Competition for Teats and Feeding Behavior by Group-Housed Dairy Calves
}

\author{
M. A. G. von Keyserlingk, L. Brusius, and D. M. Weary \\ Animal Welfare Program, Faculty of Agricultural Sciences, \\ The University of British Columbia, Vancouver, BC, Canada V6T 1 Z4
}

\begin{abstract}
Many farms using teat-based systems for supplying milk for calves provide only one or a small number of teats for a group of calves, but no previous research has addressed how competition for teats affects calf behavior or milk intake. The aim of this study was to determine how restricted access to teats affects calf competitive behavior, meal-based feeding patterns, and milk intake. Female calves $(\mathrm{n}=15)$ were divided into 5 groups of 3 calves each and fed with a teat-to-calf ratio that varied daily from 1:3 to 4:3 using a switchback design. Feeding behavior was recorded by scoring the time and duration of each sucking event. We defined meals using the frequency distribution of log intervals between visits to the teat and identified the withinmeal and between-meal distributions intersection points. Three classes of intervals were identified based on the intersection points of the distributions: 1 ) intervals $<2$ min, representing small breaks away from the teat within a meal; 2) intervals $>41$ min, providing an objective definition of a new meal; and 3) an intermediate distribution of intervals from 2 to 41 min could be included in either of the other 2 classes. Meal number showed no significant decrease with decreasing teat number. However, total time on the teat decreased from 40.2 to $32.7( \pm 2.6) \mathrm{min} / \mathrm{d}$, and milk consumption declined from 14.0 to $11.4( \pm 0.8) \mathrm{L} / \mathrm{d}$ as teat number declined from 4 to 1 . In addition, competitive interactions became more frequent when teat access was reduced; the number of times calves displaced one another from a teat increased from 18 to $41( \pm 5)$ times/d when teat number decreased from 4 to 1 . In conclusion, reduced access to teats increases competitive interactions, decreases feeding time and decreases milk intake by group-housed calves.
\end{abstract}

(Key words: calf, competition, teat feeding, feeding behavior)

Received June 1, 2004.

Accepted August 3, 2004.

Corresponding author: M. A. G. von Keyserlingk; e-mail: nina@ interchange.ubc.ca.

\section{INTRODUCTION}

Calves are social animals and keeping dairy calves in groups may provide a number of advantages to both producers and their calves. For example, rearing calves in groups allows for early social interactions that are important in the development of normal social behavior (Chua et al., 2002). Group housing also provides greater access to space, which, together with social contact, facilitates the expression of normal behavior (Jensen et al., 1997). Group rearing can also reduce the labor of cleaning pens and feeding (Kung et al., 1997).

Preweaned calves are conventionally fed 8 to $10 \%$ of their BW per day from buckets twice daily. However, recent studies have shown improvements in calf weight gains and health associated with feeding more milk. For example, Diaz et al. (2001) noted dramatically increased gains and feed-to-gain ratios by feeding larger quantities and using 3 feedings/d. One labor efficient method of providing calves with more frequent access to milk is to have milk available through a teat-based system. Calves fed milk this way can consume roughly double the amount of milk that conventionally fed calves receive, and they gain weight at roughly twice the rate (Appleby et al., 2001; Jasper and Weary, 2002).

Teat-based systems also allow calves to perform natural sucking behavior (Hammell et al., 1988), increasing the secretion of insulin and colecystokinin (de Passillé et al., 1992; Lupoli et al., 2001). Calves fed in this way are also less likely than bucket-fed calves to spend time sucking on other objects in the pen (de Passillé, 2001), and group-housed calves fed this way are less likely to suck one another (e.g., Jensen 2003). Providing one teat for each calf within the group will logically facilitate free access and reduce competitive behaviors. However, for economic and management purposes, many producers group-house calves using lower teat-to-calf ratios, such that not all calves are able to gain access to a teat at one time.

To date, there has been limited research published on the effects of competition for food by cattle (e.g., Olofsson, 1999). No work to date has addressed the effects of teat availability for grouped calves. The aim of the present study was to examine the effects of the 
teat-to-calf ratio on feeding and competitive behaviors of group-housed calves. Specifically, we measured individual milk consumption and the number of contacts and competitive displacements from the teats. Mealbased feeding patterns were calculated for dairy calves fed milk ad libitum from an artificial teat.

\section{MATERIALS AND METHODS}

The study was carried out at the University of British Columbia's Dairy Education and Research Center in Agassiz, Canada using a closed Holstein research herd. Female calves $(n=15)$ were divided into 5 groups of 3 calves each. Calves within a group were all born within $7 \mathrm{~d}$ of each other. Groups moved into the experimental pen at 21 to $42 \mathrm{~d}$ of age. This pen $(1.75 \times 7.7 \mathrm{~m})$ had wooden walls $1.3 \mathrm{~m}$ high, access openings to 3 water filled bowls, and buckets providing ad libitum access to a barley-based calf starter. Long-stemmed tall fescue grass hay was provided ad libitum in an overhead hay compartment at the rear end of the pen. Four black artificial teats (Milk-Flow Peach Teats, Skellerup Industries Ltd., New Zealand), each $118 \mathrm{~mm}$ long and 32 $\mathrm{mm}$ in diameter with two $22-\mathrm{mm}$ holes in the tapered end, were placed on the front wall of the pen at right angles to the wall at a height of $0.6 \mathrm{~m}$, with $35 \mathrm{~cm}$ between each teat. Each teat was connected to a $20-\mathrm{kg}$ milk-filled bucket via a polyethylene tube fitted with a weighted one-way valve. Each bucket rested on a digital scale ( $\pm 5 \mathrm{~g})$. Fresh milk, allowed to equilibrate to ambient temperature, was obtained from the milking parlor twice daily between 0800 to $0900 \mathrm{~h}$ and 1830 to 1930 $\mathrm{h}$ and used to replenish the milk buckets supplying milk to the teats. The containers were also refilled, if necessary, at $2200 \mathrm{~h}$ with milk from the afternoon milking. Every morning the feeding apparatus was cleaned with hot water containing bleach and rinsed with warm water.

Following an adaptation period of $3 \mathrm{~d}$, each group of calves was observed for $7 \mathrm{~d}$. The teat-to-calf ratio varied from $1: 3$ to $4: 3$, with treatments applied without replacement for $24 \mathrm{~h}$ every second day followed by a return to the control treatment (4 teats) on alternate days. This switchback design yielded $1 \mathrm{~d}$ of data per calf for each treatment with the exception of the control treatment for which there were $4 \mathrm{~d}$ of observations. The change of treatments occurred when the buckets were cleaned in the morning prior to feeding.

Individual calf milk consumption and behaviors for all 5 groups were monitored using 2 video cameras (Panasonic WV-BP330; Osaka, Japan). One camera was used to record behavior and was positioned $0.8 \mathrm{~m}$ above the pen walls and $2.1 \mathrm{~m}$ behind the teats, and a second was mounted immediately above the digital scales. Outputs from the cameras were recorded with a time-lapse videocassette recorder (Panasonic AG6540) in 24-h mode and a digital multiplexer (Panasonic WJ-FS216).

Competitive behaviors occurring when calves were drinking milk were scored as either contacts (the head of a calf sucking at a teat was physically touched by the head of another calf) or displacements (one calf displaced another from a teat). Social rank was assigned according to linear index (Hurnik et al., 1995) on the basis of the number of pen mates each calf was able to successfully displace.

A visit to the teat was recorded when a calf had the teat fully encased in its mouth for a minimum of $3 \mathrm{~s}$. Visits were deemed to end when the calf removed its mouth from the teat for $\geq 3 \mathrm{~s}$, and the time and duration of the visit was recorded. Milk intake during the visit was recorded by subtracting the milk weight at the end of the visit from the milk weight at the beginning.

\section{Feeding Behavior Measures}

Feeding behavior in cattle and other animals is typically organized in bouts (DeVries et al., 2003). Some feeding events are separated by relatively short intervals (pauses within a meal), whereas others are separated by longer periods (between meal intervals). Meals were defined using the frequency distribution of natural log intervals between visits to the teat. The software package MIX 3.1.3 (Macdonald and Green, 1988) was used to fit these mixture distributions using the method of exact maximum likelihood. This method used the mixed probability density function:

$$
g(x \mid \pi, \mu, \sigma)=\pi_{1} f\left(x \mid, \mu_{1}, \sigma_{1}\right)+\ldots+\pi_{k} f\left(x \mid, \mu_{k}, \sigma_{k}\right)
$$

where $g$ is a weighted sum of $k$ component densities. In the present study, $k=3$ represented the 3 distributions of intervals: those within meal, those between meals, and an intermediate distribution.

\section{Statistical Methods}

The analysis of treatment effects was divided into 2 parts. The first considered the calf social rank as a covariate and tested treatment within calf. However, in no case was the effect of social rank significant, so this analysis is not reported. In the second analysis, pen was treated as the observational unit (and as random effect) in a mixed model. Compound symmetry was selected as the covariance structure on the basis of best fit using SAS PROC MIXED, so subsequent analysis was with PROC GLM that uses the compound symmetry structure as default. Treatment (i.e., number of 


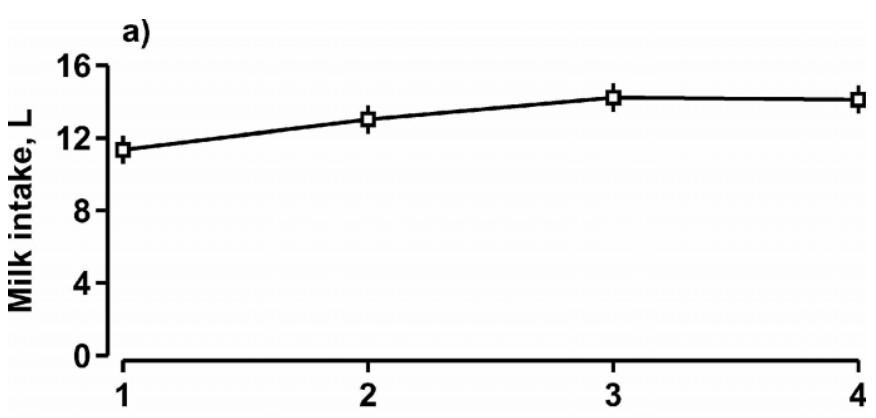

b)

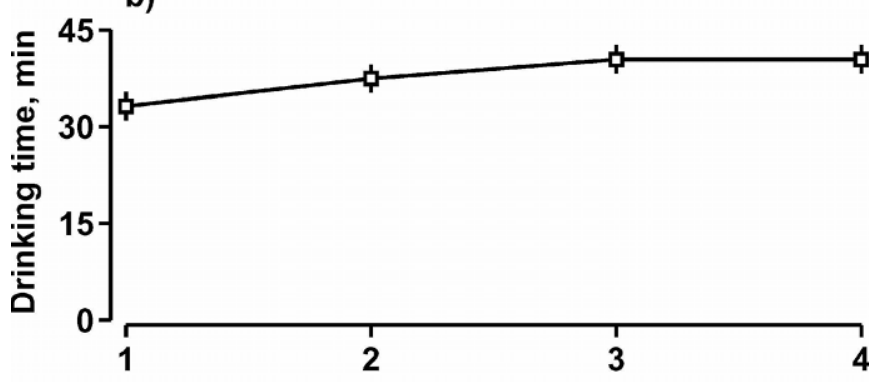

c)

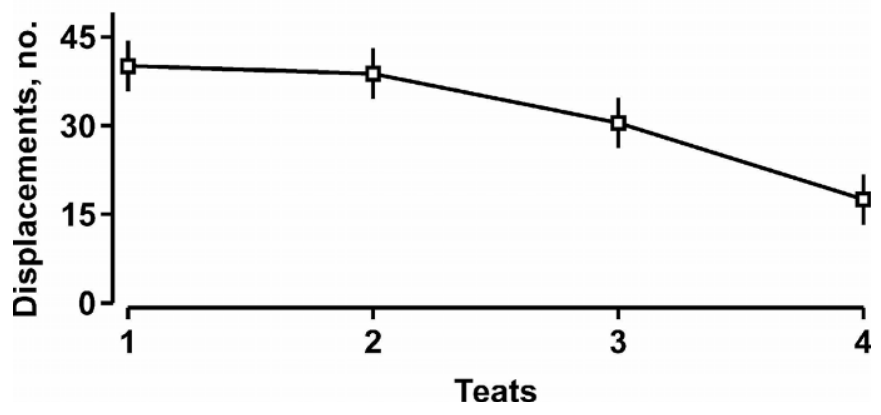

Figure 1. Calf $(\mathrm{n}=15)$ responses to $1,2,3$, or 4 teats per group of 3 calves. Mean ( \pm SEM) milk intake increased with increasing teat number (a), as did the duration of sucking events (b). The number of times calves were displaced by another calf at a teat reduced in response to increased number of available teats (c).

teats available) was tested as a continuous linear effect (1 df) after first including a term for calf group (4 df). In preliminary analyses, a quadratic term for treatment was also tested, but this was never significant and is not reported.

\section{RESULTS}

Calves drank more milk when provided with more teats $\left(F_{1,13}=5.87, P=0.03\right.$; Figure $\left.1 \mathrm{a}\right)$, such that their daily milk intake increased by $25 \%$ when provided with 4 teats compared with one teat. This increase in milk consumption was driven in part by a tendency for calves to visit teats more frequently when more were available; each calf visited the teats on average $91 \times d$ when they had access to 4 teats vs. just $64 \times \mathrm{d}$ when given access to only a single teat (with 84 and 72 visits/d on 3 and 2 teats, respectively; $\mathrm{SE}=7.5 ; \mathrm{F}_{1,13}=4.08, P=$ 0.06 ). There was no change in the average duration of visits to the nipple with increasing number of teats available $\left(\mathrm{F}_{1,13}=0.32, P>0.2\right)$, but the increased frequency of visits resulted in an increase in the total time spent at the feeder $\left(\mathrm{F}_{1,13}=5.44, P=0.04\right.$; Figure $\left.1 \mathrm{~b}\right)$.

The differences in consumption and feeding behavior were likely mediated by social interactions among the calves. Groups of calves experienced higher rates of competitive displacements when fewer teats were available $\left(\mathrm{F}_{1,13}=10.71, P<0.01\right.$; Figure 1c). Displacements from a teat were $2 \times$ as likely when calves had access to only one teat in comparison with access to 4 teats. Calves engaged in many contacts at the feeder, and the frequency of these calf-calf contacts also increased with declining teat availability $\left(\mathrm{F}_{1,13}=27.99, P<0.001\right)$. On average, 94 calf-calf contacts at the nipple were recorded each day when only a single nipple was available, compared with 43 contacts/d when calves had access to 4 nipples (83 and 52 contacts/d were recorded with 2 and 3 teats respectively; $\mathrm{SE}=7.9 ; \mathrm{F}_{1,13}=27.99$, $P<0.001$ ).

Many visits to the feeder were separated by short intervals, but for some visits, these intervals were much longer (Figure 2). The frequency distribution shows 3 classes of intervals, as defined by the MIX analysis (Macdonald and Green, 1988). The first class consists of intervals of $<2 \mathrm{~min}$, and it represents intervals within a milk meal. The last class consists of intervals $>40.7$ min, and it provides an objective definition of a new meal. The intermediate distributions, consisting of intervals from 2 to $40.7 \mathrm{~min}$, are more difficult to interpret and might be included in either of the other 2 classes.

To determine whether meal frequency varied with treatment, the frequency of teat visits that exceeded both the 2 min and 40.7 min meal criteria were compared. For both measures that meal number did not increase with increasing teat number in this study $\left(\mathrm{F}_{1,36}\right.$ $<2.07, P>0.15$ ). For example, using the 40.7 -min criterion, calves averaged $8.0 \pm 0.8 \mathrm{meals} / \mathrm{d}$ with access to one teat and $9.0 \pm 0.5$ meals $/ \mathrm{d}$ with access to 4 teats.

\section{DISCUSSION}

Milk consumption in the present study was within the range reported in other work on calves fed ad libitum in a noncompetitive environment (Chua et al., 2002; Jasper and Weary, 2002), but intake decreased when calves were forced to compete for teat access. Decreased intake as a result of increased competition was also reported by Olofsson (1999), who compared feed intake in cows fed in a noncompetitive environ- 


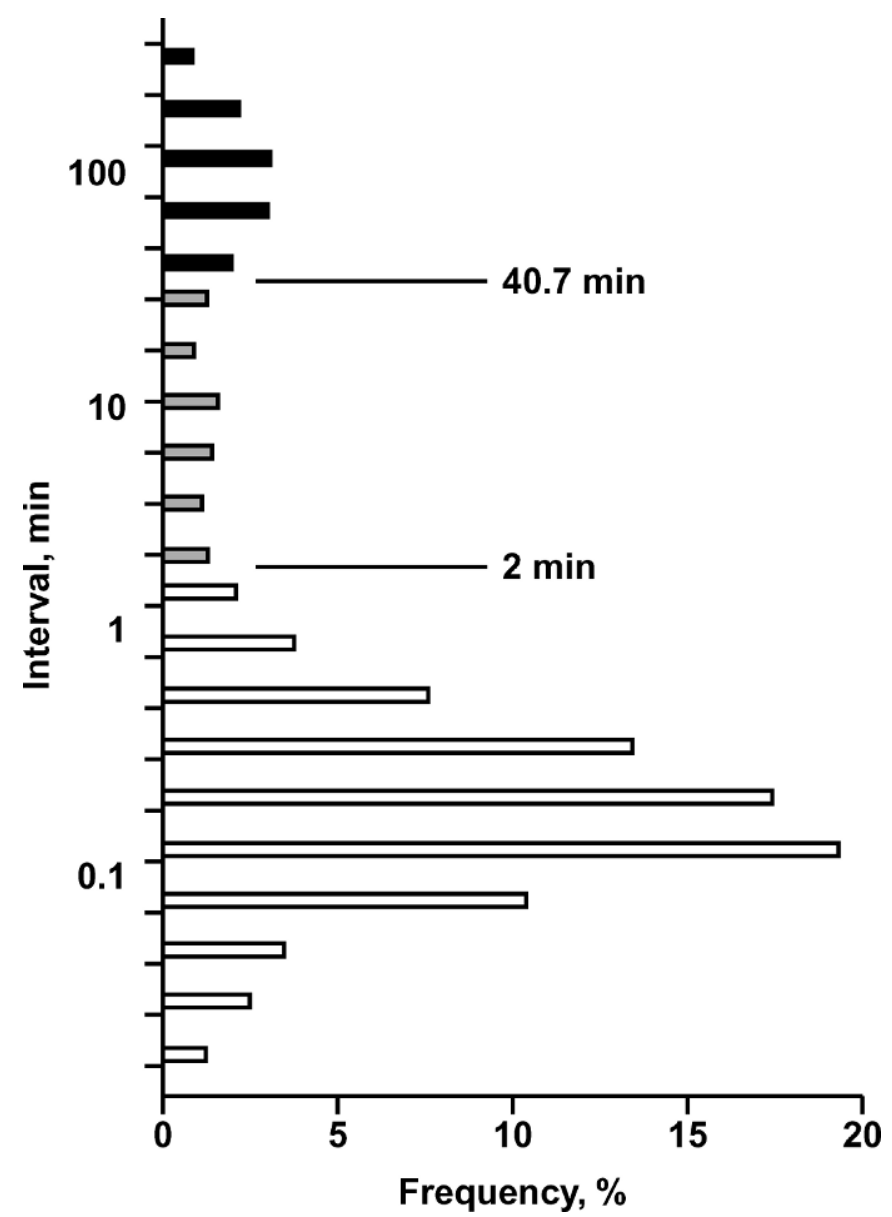

Figure 2. Relative frequency distribution (\% total observations; $\mathrm{n}=7555$ ) of the intervals between feeding bouts. The mixed distribution model fitted 3 distributions, separated at 2 and $40.7 \mathrm{~min}$. Data presented are summarized for 15 calves for $7 \mathrm{~d}$ per calf.

ment (1:1, cow: feeding station) to cows fed in a competitive environment (4:1).

The decrease in milk intake in our study was likely mediated by the increase in aggressive behavior at the teats as the ratio of calves to teats increased. Recent studies on other species have also indicated that feeding animals in ways that increase social competition can negatively affect both production and behavior. For example, group housed growing-finishing pigs show more variable weight gains when fed in more competitive environments (Georgsson and Svendsen, 2002), and this increased competition can lead to a higher incidence of skin lesions and more forced withdrawals from the feeder (Botermans et al., 2000). Such research has also shown that smaller animals housed in groups with larger animals eat less and experience lower weight gains when fed in more competitive situations (Georgsson and Svendsen, 2002).
Increased competition for teats reduced the frequency of visits to the feeder by $30 \%$ but had a negligible effect on the average duration of each feeding event, such that daily feeding times and milk intake also decreased. Hyun et al. (1998) also found that over crowding at the feeder caused pigs to decrease the number of visits to the feeder, but the pigs were able to compensate for the decreased feeder visits by increasing the duration of each visit such that daily intake was maintained. Why calves were unable to compensate is not clear. Perhaps a longer-term study would show that calves could learn to compensate by feeding at other times of the day or increasing the duration of each visit to the feeder. It is also possible that calves are unable to compensate, perhaps because they lack the natural mechanisms for dealing with these types of competitive interactions over teats. In nature, calves would rarely need to exclude other calves from a teat to gain access to milk, and indeed more mature cattle would rarely benefit by competitively excluding others from access to pasture. Another possible factor affecting the calves' ability to compensate is changes in the perceived value of the milk at different times of the day. Calves fed individually consume their largest meal just after fresh milk is provided (Appleby et al., 2001), so access to milk at this time may be especially important.

Animals typically divide their feeding time into a series of meals separated by nonfeeding intervals (Forbes, 1995). This meal patterning has recently been shown for adult dairy cows (Tolkamp et al., 2000; DeVries et al., 2003). Appleby et al. (2001) followed patterns of milk consumption for individually housed calves fed ad libitum by teat. They showed that calves arrange their milk drinking behavior into distinct meals. Appleby et al. (2001) did not report the frequency distribution of intervals between visits to the teat, so no objective estimate of meal criterion was possible. However, based on a 60-s criterion, Appleby et al. (2001) reported that calves consumed about 10 meals/d. Our estimate of meal frequency ( 8 to 9 meals/d) was based on an objective estimate of the meal criterion. Perhaps more importantly, we found that the number of meals per day was relatively insensitive to treatment differences. Thus, despite clear evidence to a meal-based patterning of milk intake, meal-based measures seem less sensitive to treatment differences than do other measures such as total daily feeding time. The work of DeVries et al. (2003) on lactating dairy cattle also showed that time spent feeding was more repeatable and more sensitive to treatment differences than were meal-based measures of feeding behavior.

The meal patterning data from the current study revealed 3 classes of intervals. The first and third classes correspond well with patterns of feeding behav- 
ior in lactating dairy cattle, with the shortest intervals clearly corresponding to short breaks within a meal and the longest to intervals between meals (Tolkamp et al., 2000; DeVries et al., 2003). However, we also observed a distribution of intermediate intervals for the milkfed calves. Yeates et al. (2001) also noted a third distribution when modeling the feeding behavior of adult cows, and they attributed these intermediate intervals to visits to the water trough. In our study, we have no data to describe calf behavior when away from the teat, but we encourage future research in this area.

In conclusion, reduced teat availability can result in increased competitive behavior, reduced feeding time, and lower milk intake for group-housed dairy calves. Commercially available computerized calf feeders are typically managed with one feeder per group of $\geq 10$ calves (e.g., Morita et al., 1999; Jensen and Holm, 2003). The results from the current study suggest that such practices may cause increased competition among calves, reduced feeding time, and reduced milk intake, unless the systems are designed and managed in such a way as to avoid these effects. Such effects may be particularly important as the dairy industry move toward the use of larger dairy milk rations for young dairy calves.

\section{ACKNOWLEDGMENTS}

We thank the staff and students at the University of British Columbia's Dairy Education and Research Center. We especially thank Danica Olenick for her help in running this experiment and Luiz Carlos Pinheiro, Machado Filho, and Maria José Hötzel for their help throughout the project. We gratefully acknowledge Trevor DeVries for his help doing the MIX analyses required for the meal criterion work. General support for the Animal Welfare Program is provided by the Natural Sciences and Engineering Research Council through the Industrial Research Chair in Animal Welfare and by contributions from the Dairy Farmers of Canada, the BC Dairy Foundation, the BC SPCA, members of the BC Veterinary Medical Association, and many others listed at www.agsci.ubc.ca/animalwelfare.

\section{REFERENCES}

Appleby, M. C., D. M. Weary, and B. Chua. 2001. Performance and feeding behaviour of calves on ad libitum milk from artificial teats. Appl. Anim. Behav. Sci. 74:191-201.

Botermans, J. A. M., L. Georgsson, B. R. Weström, A.-C. Olsson, and J. Svendsen. 2000. Effect of feeding environment on performance, injuries, plasma cortisol and behaviour in growing-finishing pigs: Studies on individual pigs housed in groups. Acta Agric. Scand. 50:250-262.
Chua, B., E. Coenen, J. van Delen, and D. M. Weary. 2002. Effects of pair verses individual housing on the behavior and performance of dairy calves. J. Dairy Sci. 85:3360-3364.

de Passillé, A. M. 2001. Sucking motivation and related problems in calves. Appl. Anim. Behav. Sci. 72:175-187.

de Passillé, A. M., J. H. M. Metz, P. Mekking, and P. R. Wiepkema. 1992. Does drinking milk stimulate sucking in young calves? Appl. Anim. Behav. Sci. 34:23-36.

DeVries, T. J., M. A. G. von Keyserlingk, D. M. Weary, and K. A. Beauchemin. 2003. Measuring the feeding behavior of lactating dairy cows in early to peak lactation J. Dairy Sci. 86:3354-3361.

Diaz, M. C., M. E. Van Amburgh, J. M. Smith, J. M. Kelsey, and E. L. Hutten. 2001. Composition of growth of Holstein calves fed milk replacer from birth to 105-kilogram body weight. J. Dairy Sci. 84:830-842.

Forbes, J. M. 1995. Voluntary Food Intake and Diet Selection in Farm Animals. CAB Int., Wallingford, United Kingdom.

Georgsson, L., and J. Svendsen. 2002. Degree of competition at feeding differentially affects behavior and performance of grouphoused growing-finishing pigs of different relative weights. J. Anim. Sci. 80:376-383.

Hammel, K. L., J. H. M. Metz, and P. Mekking. 1988. Sucking behaviour of dairy calves fed milk ad libitum by bucket or teat. Appl. Anim. Behav. Sci. 20:275-285.

Hurnik, J. F., N. J. Lewís, A. Taylor, and L. C. Pinheiro Machado. 1995. Farm Animal Behaviour-Laboratory Manual. University of Guelph, Guelph, ON, Canada.

Hyun, Y., M. Ellis, and R. W. Johnson. 1998. Effects of feeder type, space allowance, and mixing on the growth performance and feed intake pattern of growing pigs. J. Anim. Sci. 76:2771-2778.

Jasper, J., and D. M. Weary. 2002. Effects of ad libitum milk intake on dairy calves. J. Dairy Sci. 85:3054-3058.

Jensen, M. B. 2003. The effects of feeding method, milk allowance and social factors on milk feeding behavior and cross sucking in group housed calves. Appl. Anim. Behav. Sci. 80:191-206.

Jensen, M. B., and L. Holm. 2003. The effect of milk flow rate and milk allowance on feeding related behaviour in dairy calves fed by computer controlled grain feeders. Appl. Anim. Behav. Sci. 82:87-100.

Jensen, M. B., K. S. Vestergaard, C. C. Krohn, and L. Munksgaard. 1997. Effect of single versus group housing and space allowance on responses of calves during open-field tests. Appl. Anim. Behav. Sci. 54:109-121.

Kung, L., Jr., S. Demarco, L. N. Siebenson, E. Joyner, G. F. W. Haenlein, and R. M. Morris. 1997. An evaluation of two management systems for rearing calves fed milk replacer. J. Dairy Sci. 80:2529-2533.

Lupoli, B., B. Johansson, K. Uvnas-Moberg, and K. SvennerstenSjaunja. 2001. Effect of suckling on the release of oxytocin, prolactin, cortisol, gastrin, cholecystokinin, somatostatin and insulin in dairy cows and their calves. J. Dairy Res. 68:175-187.

Macdonald, P. D. M., and P. E. J. Green. 1988. User's Guide to Program MIX: An Interactive Program for Fitting Mixtures of Distributions. Release 2.3, January 1988. Ichthus Data Systems, Hamilton, Ontario, Canada.

Morita, S., S. Sugita, M. Yamamoto, S. Hoshiba, and T. Uemura. 1999. Behavioral investigation of group rearing calves in automatic milk replacer feeding system. J. Anim. Sci. 70:542-546.

Olofsson, J. 1999. Competition for total mixed diets fed for ad libitum intake using one or four cows per feeding station. J. Dairy Sci. 82:69-79.

Tolkamp, B. J., D. P. N. Schweitzer, and I. Kyriazakis. 2000. The biologically relevant unit for the analysis of short-term feeding behavior of dairy cows. J. Dairy Sci. 83:2057-2068.

Yeates, M. P., B. J. Tolkamp, D. J. Allcroft, and I. Kyriazakis. 2001. The use of mixed distribution models to determine bout criteria for analysis of animal behaviour. J. Theor. Biol. 213:413-425. 